\title{
Exploring the Role of Technology in Promoting CRM Capabilities in Direct Selling Marketing Channels: An Abstract
}

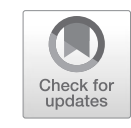

\author{
Haya Ajjan, Dana E. Harrison, and Joe F. Hair
}

\begin{abstract}
Technology has been serving as a catalyst to support company growth and performance over the last 20 years. Through the increasing acceptance of digital platforms, society has witnessed the transformation of how people interact and companies conduct business. Beyond traditional business models, direct selling companies are expanding beyond face-to-face interaction, employing and promoting the use of technology (e.g., social media sites, mobile messaging, and companysponsored websites) to reach consumers.

People are seeking opportunities within this alternative marketing channel at an increasing pace. According to the Direct Selling Association, 20.5 million people within the United States are now involved in the direct selling channel. Technology is beginning to play a critical role in the direct selling marketplace, driving and impacting the relationships among the direct selling firm, its sales force, and its customers. In the context of direct selling, technology can serve as a vehicle to promote and enable CRM capabilities such as identifying new customers, creating customer loyalty, and establishing long-term customer relationships. Due to the increasing economic impact of the direct selling channel, it is critical to explore the relationship of technology and performance of direct selling consultants. Using a sample of 195 direct selling consultants, we examine the impact of various technologies on customer relationships and salesperson performance.
\end{abstract}

\author{
H. Ajjan \\ Elon University, Elon, NC, USA \\ e-mail: hajjan@elon.edu \\ D. E. Harrison $(\bowtie)$ \\ East Tennessee State University, Johnson City, TN, USA \\ e-mail: harrisondl@etsu.edu \\ J. F. Hair \\ University of South Alabama, Mobile, AL, USA \\ e-mail: jhair@ southalabama.edu
}

